REVIEW

\title{
Treatment of jaundice in low birthweight infants
}

\author{
M J Maisels, J F Watchko
}

Exchange transfusion and phototherapy remain the staples
of intervention for the jaundiced newborn. Clinical
management of the jaundiced low birthweight infant is
discussed.

A lthough it is generally believed that preterm and low birthweight (LBW) infants are at greater risk of developing bilirubin associated brain damage than term infants, ${ }^{12}$ quantification of the magnitude of this risk has proven elusive, as has a consensus among experts on the concentration of total serum bilirubin (TSB) at which treatment should be initiated. ${ }^{4}$

Nevertheless, there is little doubt that kernicterus is currently a very rare event in premature infants in neonatal intensive care units (NICUs), ${ }^{5-7}$ although a recent report in two infants at 31 and 34 weeks of gestation, neither of whom were acutely ill and whose TSB levels were $13.1 \mathrm{mg} / \mathrm{dl}(224 \mu \mathrm{mol} / \mathrm{l})$ and $14.7 \mathrm{mg} / \mathrm{dl}$ $(251 \mu \mathrm{mol} / \mathrm{l})$, has raised renewed concerns about low bilirubin kernicterus in the premature infant. ${ }^{8}$ We do not know why kernicterus has more or less disappeared from the NICU population. It could be the result of overall improvements in the care of LBW infants and/or the aggressive use of phototherapy.

\section{EXCHANGE TRANSFUSION AND PHOTOTHERAPY}

Exchange transfusions and phototherapy remain the staples of intervention for the jaundiced newborn. Phototherapy was introduced to the medical world at the Rochford (Essex) General Hospital in 1958 by Cremer et al. ${ }^{9}$ In the closing paragraph of their paper the authors, with typical reserve, had the following to say about their new discovery: "No prospect can be entertained that this light treatment will prove a substitute for exchange transfusion in the erythroblastotic infant with active haemolysis, but the method may be turned to clinical advantage in controlling the level of serum-bilirubin in cases of jaundice of prematurity." It would be no exaggeration to say that phototherapy has succeeded beyond their wildest dreams. Just how effective it has been can be gauged from the impact it has had on the number of exchange transfusions performed for hyperbilirubinaemia $^{10}{ }^{11}$ (fig 1), and nowhere has this difference been more dramatic than in infants weighing $<1500$ g.

In a cohort of 833 infants with birth weights of 500-1500 g born in North Carolina between 1985
Arch Dis Child Fetal Neonatal Ed 2003;88:F459-F463

and 1989 , only two infants $(0.24 \%)$ underwent exchange transfusion ${ }^{10}$ and at William Beaumont Hospital in Royal Oak, Michigan, between 1988 and 1997 no exchange transfusions were performed in 1213 live births of infants weighing $<1500 \mathrm{~g}$ (fig 1). ${ }^{11}$ Certainly phototherapy, if used appropriately, ${ }^{12}$ is capable of controlling the bilirubin levels in almost all LBW infants, with the possible exception of the occasional infant with severe erythroblastosis fetalis or pronounced bruising. Furthermore, exchange transfusion, when performed at the low bilirubin levels used for treatment in LBW infants, is very inefficient and is less effective than phototherapy in achieving prolonged reduction of TSB in infants with non-haemolytic jaundice. ${ }^{13}$

\section{EXCHANGE TRANSFUSION COMPLICATIONS}

Sick, preterm infants are much more likely than term infants to experience a serious complication of exchange transfusion, such as an arrhythmia, thrombosis, thrombocytopenia, necrotising enterocolitis, and infection among others, ${ }^{14}$ or to die during or soon after the procedure. ${ }^{15}$ In a US study of 331 exchange transfusions, ${ }^{16}$ there was one death (a rate of $0.3 / 100$ procedures, $95 \%$ confidence interval (CI) 0 to 0.9 ) and significant morbidity in 5\%. In 1472 exchange transfusions, Hove and Siimes ${ }^{17}$ identified four deaths "possibly related" to the procedure, a rate of $0.3 / 100$ procedures (95\% CI 0 to 0.5 ). Jackson ${ }^{15}$ reviewed the records of the Children's Hospital Medical Center and the University of Washington Medical Center in Seattle, Washington, for 1980-1995, during which 106 infants had an exchange transfusion. Eighty one were healthy, and there were no deaths in these infants, although one child developed severe necrotising enterocolitis requiring surgery. There were 25 sick newborns; three had serious complications from the exchange transfusion and two (8\%) of these infants died (95\% CI $0 \%$ to $19 \%$ ). In three additional infants, deaths were considered "possibly due" to the exchange transfusion, so that the mortality could have been as high as $20 \%$. Four surviving infants had permanent serious sequelae: one of the 80 surviving well infants and three of $20(15 \%)$ sick infants $(95 \%$ CI $0 \%$ to $31 \%)$.

These rates, however, may not be generalisable to the current era. Experience with exchange transfusion is decreasing (fig 1 ), ${ }^{11}$ and it is

Abbreviations: LBW, low birth weight; TSB, total serum bilirubin; NICU, neonatal intensive care unit 


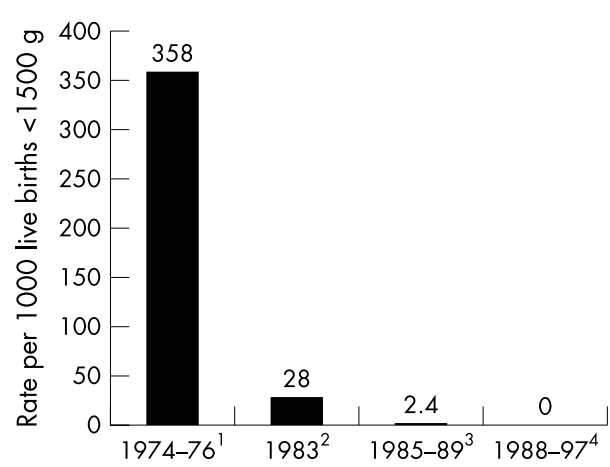

Figure 1 Number of infants in different populations with birth weight $<1500 \mathrm{~g}$ who received exchange transfusions between 1974 and 1997. Note 1: a total of 215 newborns $<1500 \mathrm{~g}$ in the National Institute of Child Health and Human Development (NICHHD) cooperative phototherapy trial assigned to the control group (did not receive phototherapy). Seventy seven of 215 patients (35.8\%) received a total of 161 exchange transfusions. In the phototherapy group, 17 of 196 $(8.7 \%)$ infants received exchange transfusions. These data are included to illustrate the frequency of exchange transfusion before the introduction of phototherapy. ${ }^{16}$ Note 2: of a total of 1338 live births $<1500 \mathrm{~g}$ in the Netherlands (1983), 37 infants (2.8\%) required at least one exchange transfusion. ${ }^{59}$ Note 3: of 833 live births $(500-1500 \mathrm{~g})$ in a 17 county region in North Carolina, two infants required an exchange transfusion $(0.24 \%) .^{10}$ Note 4: no exchange transfusions were performed in 1213 live births $<1500 \mathrm{~g}$ at William Beaumont Hospital, Royal Oak, MI between 1988 and 1997.11

reasonable to assume that, like most procedures, frequency of performance is an important determinant of risk. It is certainly very difficult, if not impossible, to teach paediatric residents in the United States to perform exchange transfusions, and there is legitimate concern about our ability to train even neonatal fellows to perform this once common procedure. Indeed, with newer phototherapy technologies emerging, ${ }^{18}$ as well as the potential for pharmacological inhibition of bilirubin production, ${ }^{19}{ }^{20}$ exchange transfusion in the NICU is in danger of becoming extinct. As discussed previously, ${ }^{3}$ the validity of traditional criteria for exchange transfusion in the LBW population has been questioned, and the introduction of more effective phototherapy for these infants has rendered much of the debate on exchange transfusion in this population moot. ${ }^{511}$

\section{MANAGEMENT OF NEONATAL JAUNDICE IN PRETERM NEONATES}

As discussed above and in the preceding review, ${ }^{3}$ the inability to relate specific TSB levels in LBW infants to developmental outcome or pathological kernicterus has made the framing of guidelines for the use of phototherapy and exchange transfusion in these infants a capricious exercise at best and one for which no claim of an "evidence base" can be made. Reference to tables 1-3 illustrates a range of TSB levels for intervention in various circumstances. These guidelines are provided by different experts, none of whom, we believe, would make any claim for the greater validity of one approach over another. The aim of treatment is to prevent bilirubin related neurodevelopmental handicap while not causing harm. The almost complete disappearance of pathological kernicterus in this population suggests that, if this is the result of fairly aggressive phototherapy, used on a sliding scale as shown in tables $1-3$, we must be doing something right. On the other hand, both the absence of any other evidence (in the form of controlled clinical trials) to support this approach ${ }^{4}$ (B Morris, personal communication, 2002) and the possibility that phototherapy has other, less desirable, consequences should give us pause for thought.
Table 1 Guidelines for the use of phototherapy and exchange transfusion in low birthweight infants based on birth weight ${ }^{57}$

Total bilirubin level (mg/dl $\left.(\mu \mathrm{mol} / \mathrm{l})^{*}\right)$

\begin{tabular}{lll} 
Birth weight $(g)$ & Phototherapy & Exchange transfusion $\ddagger$ \\
\hline$\leqslant 1500$ & $5-8(85-140)$ & $13-16(220-275)$ \\
$1500-1999$ & $8-12(140-200)$ & $16-18(275-300)$ \\
$2000-2499$ & $11-14(190-240)$ & $18-20(300-340)$ \\
\hline
\end{tabular}

Note that these guidelines reflect ranges used in neonatal intensive care units. They cannot take into account all possible situations. Lower bilirubin concentrations should be used for infants who are sick-for example, presence of sepsis, acidosis, hypoalbuminaemia-or have haemolytic disease.

*Consider initiating treatment at these levels. Range allows discretion based on clinical conditions or other circumstances. Note that bilirubin levels refer to total serum bilirubin concentrations. Direct reacting or conjugated bilirubin levels should not be subtracted from the total. tUsed at these levels and in therapeutic doses, phototherapy should, with few exceptions, eliminate the need for exchange transfusions. tLevels for exchange transfusion assume that bilirubin continues to rise or remains at these levels despite intensive phototherapy.

Table 2 Guidelines for use of phototherapy and exchange transfusion in preterm infants based on gestational age ${ }^{58}$

\begin{tabular}{llll}
\hline & \multicolumn{3}{l}{ Total bilirubin level $(\mathrm{mg} / \mathrm{dl}(\mu \mathrm{mol} / \mathrm{l}))$} \\
\cline { 2 - 4 } $\begin{array}{l}\text { Gestational } \\
\text { age (weeks) }\end{array}$ & Phototherapy & \multicolumn{2}{l}{ Exchange transfusion } \\
\cline { 2 - 4 } & & \multicolumn{2}{l}{ Sick* Well } \\
\hline 36 & $14.6(250)$ & $17.5(300)$ & $20.5(350)$ \\
32 & $8.8(150)$ & $14.6(250)$ & $17.5(300)$ \\
24 & $5.8(100)$ & $11.7(200)$ & $14.6(250)$ \\
& $4.7(80)$ & $8.8(150)$ & $11.7(200)$ \\
\hline *Rhesus disease, perinatal asphyxia, hypoxia, acidosis, hypercapnia.
\end{tabular}

Table 3 Guidelines according to birth weight for exchange transfusion in low birthweight infants based on total serum bilirubin $(\mathrm{mg} / \mathrm{dll}$ ) and bilirubin/albumin ratio $(\mathrm{mg} / \mathrm{g})(\text { whichever comes first) })^{35}$

\begin{tabular}{|c|c|c|c|}
\hline \multicolumn{4}{|c|}{$<1250$ g 1250-1499 g 1500-1999 g 2000-2499 g } \\
\hline \multicolumn{4}{|l|}{ Standard risk } \\
\hline Total bilirubin 13 & 15 & 17 & 18 \\
\hline $\begin{array}{l}\text { B/A ratio } \\
\text { High risk* }\end{array}$ & 6.0 & 6.8 & 7.2 \\
\hline Total bilirubin 10 & 13 & 15 & 17 \\
\hline $\mathrm{B} / \mathrm{A}$ ratio & 5.2 & 6.0 & 6.8 \\
\hline
\end{tabular}

*Risk factors: Apgar $<3$ at five minutes; $\mathrm{PaO}_{2}<40 \mathrm{~mm} \mathrm{Hg} \geqslant 2 \mathrm{~h}$; $\mathrm{pH} \leqslant 7.15 \geqslant 1 \mathrm{~h}$; birth weight $<1000 \mathrm{~g}$; haemolysis; clinical or central nervous system deterioration; total protein $\leqslant 4 \mathrm{~g} / \mathrm{dl}$ or albumin $\leqslant 2.5 \mathrm{~g} / \mathrm{dl}$. $\mathrm{B} / \mathrm{A}$ ratio, Bilirubin/albumin ratio.

Bilirubin is a powerful antioxidant ${ }^{21}$ and may have a physiological role as an antioxidant in the human neonate. ${ }^{22}{ }^{23}$ It has also been suggested that keeping TSB levels low with phototherapy (and thus reducing the antioxidant level) could facilitate the development of retinopathy of prematurity. In a study of 157 23-26 week gestation infants, however, no relation was found between TSB levels and retinopathy of prematurity. ${ }^{24}$ More than $90 \%$ of extremely LBW infants (birth weights $<1000$ g) receive phototherapy, and concern for the possible negative consequences of aggressive phototherapy has led the NICHHD Neonatal Research Network to initiate a prospective randomised trial 
Table 4 Guidelines for initiating phototherapy and exchange transfusions (NICHHD Neonatal Research Network Trial) (B Morris, personal communication, 2002)

\begin{tabular}{|c|c|c|c|c|}
\hline \multirow[b]{2}{*}{$\begin{array}{l}\text { Birth } \\
\text { weight (g) }\end{array}$} & \multicolumn{2}{|c|}{ Aggressive management } & \multicolumn{2}{|c|}{ Conservative management } \\
\hline & $\begin{array}{l}\text { Phototherapy } \\
\text { begins }\end{array}$ & $\begin{array}{l}\text { Exchange } \\
\text { transfusion }\end{array}$ & $\begin{array}{l}\text { Phototherapy } \\
\text { begins }\end{array}$ & $\begin{array}{l}\text { Exchange } \\
\text { transfusion }\end{array}$ \\
\hline $501-750$ & $\begin{array}{l}\text { ASAP after } \\
\text { enrollment }\end{array}$ & $\geqslant 13.0 \mathrm{mg}$ & $g / d l$ & $\geqslant 13.0 \mathrm{mg} / \mathrm{dl}$ \\
\hline $751-1000$ & $\begin{array}{l}\text { ASAP after } \\
\text { enrollment }\end{array}$ & $\geqslant 15.0 \mathrm{mg}$ & $g / d l$ & $\geqslant 15$ \\
\hline
\end{tabular}

Enrollment is expected within 12-36 hours after birth, preferably between 12 and 24 hours.

ASAP, As soon as possible.

to compare aggressive with conservative phototherapy in these infants (B Morris, personal communication, 2002). Table 4 shows the TSB levels for intervention with phototherapy and exchange transfusion in this continuing trial. The primary outcome will be death or neurodevelopmental impairment at 18-22 months corrected age. The results of this study should provide important information about the risks and benefits of phototherapy in this vulnerable population.

Although the "aggressive" arm of the NICHHD study (table 4) calls for phototherapy to be used prophylactically, in the absence of a documented increase in TSB, this is a practice that currently should be discouraged. In a randomised trial in LBW infants, prophylactic phototherapy (treatment initiated directly after birth) was compared with phototherapy when the TSB reached $5 \mathrm{mg} / \mathrm{d}(85 \mu \mathrm{mol} / \mathrm{l}) .{ }^{25}$ Prophylactic phototherapy significantly lengthened the duration of treatment but had no beneficial effect on the bilirubin levels. This is hardly surprising as phototherapy probably acts on bilirubin in the capillaries of the skin or interstitial space, ${ }^{26}$ and until there is some increase in the serum bilirubin, phototherapy is ineffective.

Tables 1-3 provide suggested guidelines for the management of hyperbilirubinaemia in LBW infants. Phototherapy is generally used according to a sliding scale: the lower the birth weight or gestation, the lower the TSB level at which phototherapy is instituted. However, as discussed above, there is little good evidence to support this practice ${ }^{4}$ except perhaps for the influence of gestation on bilirubin-albumin binding. ${ }^{27}{ }^{28}$ These guidelines reflect ranges used in different NICUs and cannot take into account all possible situations.

\section{ALBUMIN BINDING AND THE BILIRUBIN/ALBUMIN RATIO}

Bilirubin is transported in the plasma tightly bound to albumin, and the portion that is unbound or loosely bound can more readily leave the intravascular space and cross the intact blood-brain barrier. ${ }^{29}$ Rises in unbound bilirubin have been associated with kernicterus in sick, preterm newborns. ${ }^{30}{ }^{31}$ In addition, raised unbound bilirubin concentrations are more closely associated than TSB levels with transient abnormalities in the audiometric brain stem response in both term ${ }^{32}$ and preterm ${ }^{33}$ infants. There are, however, no contemporary long term studies relating unbound bilirubin concentrations in LBW infants to developmental outcome. In one follow up of 224 infants born in 1974-1976 with birth weights below $2000 \mathrm{~g}$ and evaluated at age 6 years, no relation was found between measures of bilirubin-albumin binding and intelligence quotient scores. ${ }^{34}$ In addition, clinical laboratory measurement of unbound bilirubin is not generally available.

The ratio of bilirubin $(\mathrm{mg} / \mathrm{dl})$ to albumin $(\mathrm{g} / \mathrm{dl})$ does correlate with measured unbound bilirubin in newborns ${ }^{35}$ and has been used as an approximate surrogate for the measurement of unbound bilirubin. ${ }^{35}$ It must be recognised, however, that albumin binding capacity varies significantly between newborns, ${ }^{35}{ }^{36}$ is impaired in sick infants, ${ }^{27} 3637$ and increases with increasing gestational age ${ }^{27} 28$ and postnatal age. ${ }^{28}{ }^{38}$ Furthermore, the risk of bilirubin encephalopathy is not simply a function of the TSB level or the concentration of unbound bilirubin, but is a combination of both-that is, the total amount of bilirubin available (the miscible pool of bilirubin) as well as the tendency of bilirubin to enter the tissue (the unbound bilirubin concentration).$^{35}$ An additional factor is the susceptibility of the cells of the central nervous system to damage by bilirubin. ${ }^{39}$ The bilirubin/albumin ratio can therefore be used together with, but not in lieu of, the TSB level as an additional factor in determining the need for exchange transfusion ${ }^{28}$ (table 3 ).

\section{USING PHOTOTHERAPY EFFECTIVELY IN THE LBW INFANT}

Given that the mainstay of treatment for neonatal jaundice in preterm infants is phototherapy, we review aspects of this treatment that influence its effectiveness.

\section{Light source and dose}

We use phototherapy in the NICU at quite low TSB levels, to prevent the TSB from rising to a level where exchange transfusion may be necessary. Like any therapeutic agent, phototherapy should be administered in an adequate dose, and this can be estimated quite easily using a radiometer obtained from the manufacturer of the phototherapy device. Figure 2 illustrates the dose-response relation between the irradiance used and the rate at which the TSB level declines in term infants under phototherapy. ${ }^{40}$

Most commonly used phototherapy units deliver enough output in the blue-green region of the visible spectrum to be effective for conventional phototherapy in LBW infants. ${ }^{41}$ On the other hand, if bilirubin levels approach a range at which exchange transfusion is indicated, then more intensive therapeutic forms of phototherapy should be used. ${ }^{12}$ This is achieved by increasing the irradiance and the surface area exposed (see below). The most effective light source currently commercially available is that provided by special blue fluorescent tubes. ${ }^{41}$ These tubes are labelled F20 T12/BB or PL52/20W, and they provide much greater irradiance than regular blue tubes (labelled F20T12/B) (fig 3). Special blue tubes are more effective because they provide light with wavelengths predominantly in the blue-green spectrum,

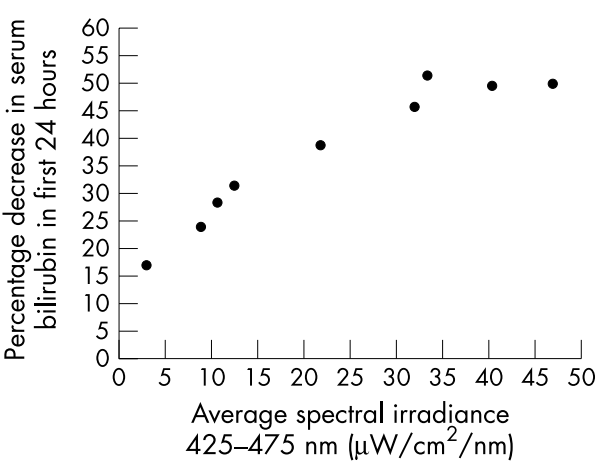

Figure 2 Relation between average spectral irradiance and decrease in serum bilirubin concentration. Full term infants with non-haemolytic hyperbilirubinaemia were exposed to special blue lights (Phillips TL 52/ $20 \mathrm{~W}$ ) of different intensities. Spectral irradiance was measured as the average of readings at the head, trunk, and knees. Drawn from the data of Tan. ${ }^{40}$ 


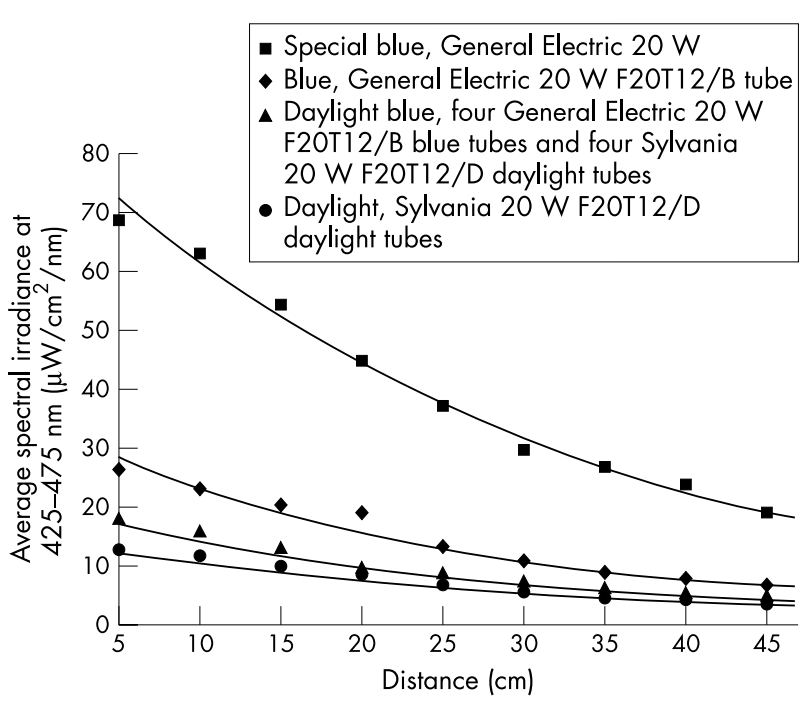

Figure 3 Effect of light source and distance from the light source to the infant on average spectral irradiance. Measurements were made across the $425-475 \mathrm{~nm}$ band using a commercial radiometer (Olympic Bilimeter Mark II). The phototherapy unit was fitted with eight 24 inch fluorescent tubes. Curves were plotted using linear curve fitting (True Epistat; Epistat Services, Richardson, Texas, USA). The best fit is described by the equation $y=A e^{B \times} .{ }^{12}$

where light penetrates the skin well and is absorbed maximally by bilirubin. ${ }^{41}$

Fibre optic phototherapy systems have several advantages over conventional phototherapy. Non-distressed neonates can be swaddled or dressed with the fibre optic blanket placed inside the blankets or clothes. These infants do not need to have their eyes covered (a major benefit to the family), but if the infant is lying (undressed) on a fibre optic pad, eye patching is advisable. In some studies of LBW infants, fibre optic phototherapy has been as effective as conventional phototherapy ${ }^{42}{ }^{43}$ but it is less effective when compared with special blue phototherapy lamps. ${ }^{44}$

\section{Distance from the light}

Spectral irradiance increases dramatically as the distance between the light source and infant decreases, and this effect is greatest when special blue tubes are used (fig 3). If bilirubin levels are rising in spite of conventional phototherapy-for example, severely bruised infants or those with haemolytic disease-a free standing bank of special blue fluorescent tubes should be placed about $10 \mathrm{~cm}$ from the infant. This proximity is accomplished by placing the fluorescent bank of lights between the radiant warmer and the infant and cannot be achieved when the infant is in an incubator. If halogen spot phototherapy lamps are used, they must not be positioned closer to the infant than recommended by the manufacturer because of the risk of a burn. In addition, if two or more halogen lamps are used, they should never be focused on the same area of the infant's skin, as this may also cause a burn.

\section{Surface area}

The efficacy of phototherapy is closely related to the surface area of the infant exposed to the phototherapy lights, and the simplest way of increasing the surface area exposed is to place fibre optic pads below the infant with phototherapy lamps above. In preterm infants, this type of "double phototherapy" is approximately twice as effective as single phototherapy. ${ }^{44} 45$ If this intervention does not produce the desired decrease in the serum bilirubin level, additional exposure can be achieved by lining the sides of the radiant warmer or the incubator with a reflecting material such as white linen or aluminium foil.

\section{Intermittent versus continuous phototherapy}

Clinical studies comparing intermittent with continuous phototherapy have produced conflicting results, but in most circumstances phototherapy does not need to be continuous. As long as the serum bilirubin level is being controlled, phototherapy can certainly be interrupted during feeding or parental visits. It is particularly important during parental visits to switch off the phototherapy lights and remove the eye patches. Not being able to see their baby's eyes is extremely disconcerting for parents.

\section{Hydration}

Some studies suggest that phototherapy significantly increases insensible water loss in preterm infants, ${ }^{46}{ }^{47}$ but more recently it has been shown that as long as skin temperature is kept constant (by servo-control) and infants are not subjected to heat stress, phototherapy does not lead to an increase in oxygen consumption or insensible water loss through the skin or the respiratory tract. ${ }^{47} 48$ As we have simple and effective ways of monitoring newborn hydration (such as a daily weight and measurements of electrolytes), there is no indication for providing additional fluids routinely to infants who are receiving phototherapy. They should, of course, be kept adequately hydrated, not because phototherapy produces dehydration but because adequate urine output is important for effective phototherapy. The bilirubin isomer, lumirubin, is excreted in the bile and the urine, and lumirubin excretion appears to be an important element in the bilirubin lowering function of phototherapy. ${ }^{41}$

\section{Complications}

Major complications associated with phototherapy are exceptionally rare. Perhaps the most important clinical complication encountered during the use of phototherapy in the LBW infant is that associated with the presence of direct hyperbilirubinaemia or cholestatic jaundice (usually after prolonged parental nutrition). When infants with direct hyperbilirubinaemia are exposed to phototherapy, they may develop a dark, greyish-brown discoloration of the skin, serum, and urine (the "bronze baby syndrome"). ${ }^{49} 50$ The pathogenesis of this syndrome is unknown, but it is possibly related to the accumulation of porphyrins or other pigments in the plasma in the presence of cholestasis. ${ }^{49-51}$ Although few deleterious consequences of the bronze baby syndrome have been described, two infants with this syndrome who died were shown to have kernicterus at autopsy. ${ }^{50}{ }^{52}$ Except for these case reports, there are no other reports of significant complications in infants who develop the bronze baby syndrome, although impaired binding of bilirubin to albumin has been detected in three infants with this syndrome ${ }^{53}{ }^{54}$ and in infants with cholestasis. ${ }^{53}$ If there is a need for phototherapy, the presence of direct hyperbilirubinaemia should not be considered a contraindication to its use, particularly in the sick newborn, and, as a rule, the direct serum bilirubin level should not be subtracted from the total bilirubin concentration when decisions are made about initiating phototherapy or an exchange transfusion (tables 1-3). In infants who develop the bronze baby syndrome, exchange transfusion should be considered if phototherapy does not lower TSB. Because of the paucity of data, however, firm recommendations cannot be made. Rarely, purpuric bullous eruptions have also been described in infants with severe cholestatic jaundice receiving phototherapy. ${ }^{55} 56$ 


\section{Authors' affiliations}

M J Maisels, Department of Pediatrics, William Beaumont Hospital, Royal Oak, MI 48073, USA

J F Watchko, Division of Neonatology and Developmental Biology, Department of Pediatrics, University of Pittsburgh School of Medicine, Pittsburgh, PA 15213, USA

\section{REFERENCES}

1 Gartner LM, Snyder RN, Chabon RS, et al. Kernicterus: high incidence in premature infants with low serum bilirubin concentration. Pediatrics 1970:45:906

2 Watchko JF, Oski FA. Kernicterus in preterm newborns: past, present and future. Pediatrics 1992;90:707-15.

3 Watchko JF, Maisels MJ. Jaundice in low birth weight infants: pathobiology and outcome. Arch Dis Child Fetal Neonatal Ed 2003;00:F000.

4 Cashore W. Bilirubin and jaundice in the micropremie. Clin Perinatol 2000;27:171-9.

5 Watchko J, Claassen D. Kernicterus in premature infants: current prevalence and relationship to NICHHD phototherapy study exchange criteria. Pediatrics 1994;93:996-9.

6 Pearlman MA, Gartner LM, Lee K-S, et al. Absence of kernicterus in low-birthweight infants from 1971 through 1976: comparison with findings in 1966 and 1967. Pediatrics 1978;62:460-4.

7 Maisels MJ. Clinical studies of the sequelae of hyperbilirubinemia. In Levine RL, ed. Hyperbilirubinemia in the newborn, Report of the 85th Ross Conference on Pediatric Research. Columbus, $\mathrm{OH}$ : Ross Laboratories, 1983:26-38

8 Sugama S, Soeda A, Eto Y. Magnetic resonance imaging in three children with kernicterus. Pediatr Neurol $2001 ; 25: 328-31$.

9 Cremer RJ, Perryman PW, Richards DH. Influence of light on the hyperbilirubinemia of infants. Lancet 1958;1:1094-17.

10 O'Shea TM, Dillard RG, Klinepeter KD, et al. Serum bilirubin levels, intracranial hemorrhage, and the risk of developmental problems in very low birth weight infants. Pediatrics 1992;90:888-92.

11 Maisels MJ. Phototherapy: traditional and nontraditional. J Perinatol 2001;21:S93-7.

12 Maisels MJ. Why use homeopathic doses of phototherapy? Pediatrics 1996;98:283-7.

13 Tan KL. Comparison of the effectiveness of phototherapy and exchange transfusion in the management of nonhemolytic neonatal hyperbilirubinemia. J Pediatr 1975;87:609-12.

14 Watchko JF. Exchange transfusion in the management of neonatal hyperbilirubinemia. In: Maisels MJ, Watchko JF, eds. Neonatal jaundice. London: Harwood Academic Publishers, 2000:169-76.

15 Jackson JC. Adverse events associated with exchange transfusion in healthy and ill newborns. Pediatrics 1997;99:5. www.pediatrics.org/cgi/content/ full/99/5/e7

16 Keenan WJ, Novak KK, Sutherland JM, et al. Morbidity and mortality associated with exchange transfusion. Pediatrics 1985:75(suppl):417-21.

17 Hovi L, Siimes MA. Exchange transfusion with fresh heparinized blood is a safe procedure: experiences from 1069 newborns. Acta Paediatr Scand 1985;74:360-5.

18 Seidman DS, Moise J, Ergaz Z. A new blue light-emitting phototherapy device: a prospective randomized controlled study. J Pediatr 2000;136:771-4

19 Kappas A, Drummond G, Henschke C, et al. Direct comparison of Snmesoporphyrin, an inhibitor of bilirubin production, and phototherapy in controlling hyperbilirubinemia in term and near-term newborns. Pediatrics 1995:95:468-74.

20 Kappas A, Drummond GS, Munson DP, et al. Sn-mesoporphyrin interdiction of severe hyperbilirubinemia in Jehovah's Witness newborns as an alternative to exchange transfusion. Pediatrics $2001 ; 108: 1374-7$

21 McDonagh AF. Is bilirubin good for you? Clin Perinatol 1990;17:359-69.

22 Hegyi T, Goldie E, Hiatt M. The protective role of bilirubin in oxygen radical disease of the preterm infant. J Perinatol 1994;14:296-300.

23 Gopinathan V, Miller NJ, Milner AD, et al. Bilirubin and ascorbate antioxidant activity in neonatal plasma. FEBS Lett 1994;349:197-200.

24 DeJonge MH, Khuntia A, Maisels MJ, et al. Bilirubin levels and severe retinopathy of prematurity in 23-26 week estimated gestational age infants. J Pediatr 1999; 135: 102-4.

25 Curtis-Cohen M, Stahl GE, Costarino AT, et al. Randomized trial of prophylactic phototherapy in the infant with very low birth weight. J Pediatr 1987:107:121-4.

26 Maisels MJ. Phototherapy. In: Maisels MJ, Watchko JF, eds. Neonatal jaundice. London: Harwood Academic Publishers, 2000:177-204

27 Cashore WJ, Oh W, Brodersen R. Reserve albumin and bilirubin toxicity index in infant serum. Acta Paediatr Scand 1983:72:415-19.

28 Ebbsen F, Nyboe J. Postnatal changes in the ability of plasma albumin to bind bilirubin. Acta Paediatr Scand 1983;72:665-70.
29 Bratlid D. How bilirubin gets into the brain. Clin Perinatol 1990;17:449-65.

30 Cashore WJ, Oh W. Unbound bilirubin and kernicterus in low birthweight infants. Pediatrics 1982;69:481-5.

31 Nakamura $H$, Yonetani $M$, Uetani $Y$, et al. Determination of serum unbound bilirubin for prediction of kernicterus in low birth weight infants. Acta Paediatr Jpn 1992;54:642-7.

32 Funato $M$, Tamai $H$, Shimada $S$, et al. Vigintiphobia, unbound bilirubin, and auditory brainstem responses. Pediatrics 1994;93:50-3.

33 Amin SB, Ahlfors CE, Orlando MS, et al. Bilirubin and serial auditory brainstem responses in premature infants. Pediatrics 2001;107:664-70.

34 Scheidt PC, Graubard BI, Nelson KB, et al. Intelligence at six years in relation to neonatal bilirubin level: follow-up of the National Institute of Child Health and Human Development Clinical Trial of Phototherapy. Pediatrics 1991;87:797-805.

35 Ahlfors CE. Criteria for exchange transfusion in jaundiced newborns. Pediatrics 1994:93:488-94.

36 Cashore WJ. Free bilirubin concentrations and bilirubin-binding affinity in term and preterm infants. J Pediatr 1980;96:521-7.

37 Ebbesen F, Brodersen R. Risk of bilirubin acid precipitation in preterm infants with respiratory distress syndrome: considerations of blood/brain bilirubin transfer equilibrium. Early Hum Dev 1982;6:341-55.

38 Esbjorner E. Albumin binding properties in relation to bilirubin and albumin concentrations during the first week of life. Acta Paediatr Scand $1991 ; 80: 400-5$

39 Wennberg RP. Cellular basis of bilirubin toxicity. NY State J Med $1991 ; 91: 493-6$.

40 Tan KL. The pattern of bilirubin response to phototherapy for neonatal hyperbilirubinemia. Pediatr Res 1982;16:670-4

41 Ennever JF. Blue light, green light, white light, more light: treatment of neonatal jaundice. Clin Perinatol 1990; 17:467-81.

42 Pezzati M, Biagiotti R, Vangi V, et al. Changes in mesenteric blood flow response to feeding: conventional versus fiberoptic phototherapy. Pediatrics 2000;105:350-3.

43 Costello SA, Nyikal J, Yu VY, et al. BiliBlanket phototherapy system versus conventional phototherapy: a randomized controlled trial in preterm infants [see comments]. J Paediatr Child Health 1995;31:11-13.

44 Donzelli GP, Moroni M, Pratesi S, et al. Fibreoptic phototherapy in the management of jaundice in low birthweight neonates. Acta Paediatr 1996:85:366-70.

45 Holtrop PC, Ruedisueli K, Maisels MJ. Double versus single phototherapy in low birth weight newborns. Pediatrics 1992;90:674-7.

46 Wu PYK, Hodgman JE. Insensible water loss in preterm infants: changes with post-natal development and non-ionizing radiant energy. Pediatrics 1974;54:704-12

47 Kjartansson S, Hammarlund K, Sedin G. Insensible water loss from the skin during phototherapy in term and preterm infants. Acta Paediatr 1992:81:764-8

48 Fok T, Gu J-S, Lim C, et al. Oxygen consumption and resting energy expenditure during phototherapy in full term and preterm newborn infants. Arch Dis Child Fetal Neonatal Ed 2001;85:F49-52.

49 Rubaltelli FF, Jori G, Reddi E. Bronze baby syndrome: a new porphyrinrelated disorder. Pediatr Res 1983;17:327-30.

50 Rubaltelli FF, Da Riol R, D'Amore E, et al. The bronze baby syndrome: evidence of increased tissue concentration of copper porphyrins. Acta Paediatr 1996;85:381-4.

51 Onishi I, Itoh S, Isobe K. Mechanism of development of bronze baby syndrome in neonates treated with phototherapy. Pediatrics 1982;69:273-6.

52 Clark CF, Torii S, Hamamoto Y, et al. The "bronze baby" syndrome: postmortem data. J Pediatr 1976;88:461-4.

53 Ebbesen $\mathbf{F}$. Low reserve albumin for binding of bilirubin in neonates with deficiency of bilirubin excretion and bronze baby syndrome. Acta Paediat Scand 1982:71:415-10.

54 Kopelman AE, Brown RS, Odell GB. The "bronze" baby syndrome: a complication of phototherapy. J Pediatr 1972;81:466-72.

55 Mallon E, Woinarowska F, Hope $\mathrm{P}$, et al. Neonatal bullous eruption as a result of transient porphyrinemia in a premature infant with hemolytic disease of the newborn. J Am Acad Dermatol 1995;33:333-6.

56 Paller AS, Eramo LR, Farrell EE, et al. Purpuric phototherapy-induced eruption in transfused neonates: relation to transient porphyrinemia. Pediatrics 1997:100:360-4.

57 Maisels MJ. Jaundice. In: Avery GB, Fletcher MA, MacDonald MG, eds. Neonatology: pathophysiology and management of the newborn. Philadelphia: JB Lippincott, Co, 1999:765-819.

58 Ives NK. Neonatal jaundice. In: Rennie JM, Roberton NRC, eds. Textbook of neonatology. New York: Churchill Livingston, 1999:715-32.

59 van de Bor M, van Zeben-van der Aa TM, Verloove-Vanhorick SP, et al. Hyperbilirubinemia in very preterm infants and neurodevelopmental outcome at two years of age: results of a national collaborative survey. Pediatrics 1989;83:915-20. 